\title{
Probabilistic Analysis of Voltage Divider Ratios
}

Dalibor S. Arbutina

Public Company

Nuclear Facilities of Serbia

Aleksandra I. VasićMilovanović

University of Belgrade Faculty of Mechanical Engineering

Uroš D. Kovačević

University of Belgrade Faculty of Mechanical Engineering
Tolerance of modern resistors typically ranges from $0.1 \%$ to $1 \%$. From the probabilstic viewpoint, this is taken to mean that the corresponding resistance can be treated as a random variable, with an appropriate probability density function $(P D F)$. We derive an expression for the $P D F$ of a two-resistor voltage divider's transfer ratio, when the resistances in the divider are assigned uniform distributions. Plots of the obtained analytical expression, for various combinations of nominal resistances and tolerances of the two resistors, are compared to those produced by numerical (Monte Carlo) simulations. The asymmetrical character of the obtained resultant PDF, caused by non-linearity of the divider's circuit function, implies that the nominal, the mean and the most probable value of the divider's ratio can all differ. For normally distributed resistances in the two-resistor divider, analytical approach becomes complex, while Monte Carlo simulations readily provide the plots of voltage ratio PDFs and calculate the values of their parameters.

Keywords: voltage divider, tolerance, resistors, probability density function, Monte Carlo method.

\section{INTRODUCTION}

Manufacturing tolerance of an electrical component is the limit of unintended deviation from a nominal value of the component's characteristic quantity. Thick film resistors, when first manufactured, had resistance tolerances of $5 \%$, but standard tolerances have improved to about $1 \%$. Thin film resistors are usually specified with tolerances between 0.1 and $1 \%$. Certain resistor types, such as ultra-precision foil resistors, have tolerances tighter than these, on the order of $0.005 \%$. From the probabilistic viewpoint, this is taken to mean that the corresponding resistance can be treated as a random variable, with an appropriate probability density function (PDF) assigned to it [1].

A defining parameter of a resistive circuit, such as its equivalent resistance or transfer ratio, is generally a non-linear function of the resistances that make up the circuit, the only exception being the equivalent resistance of a serial connection of resistors. Even if distributions with symmetrical PDFs, such as uniform or normal, are adopted for the parameters of the components the circuit comprises, non-linearity of the circuit function gives rise to asymmetry in the PDF of the circuit's parameter. The asymmetry of the PDF causes the nominal, the mean and the most probable value of the circuit parameter to differ [2].

This paper examines the voltage ratio of a resistive voltage divider from the probabilistic point of view. Percentage tolerances of the resistors constituting the divider are treated as maximum relative uncertainties

Received: January 2019, Accepted: April 2019

Correspondence to: Prof. Aleksandra Vasić-

Milovanović, Faculty of Mechanical Engineering,

Kraljice Marije 16, 11120 Belgrade 35, Serbia

E-mail: avasic@mas.bg.ac.rs

doi: $\mathbf{1 0 . 5 9 3 7 / f m e t 1 9 0 3 6 2 4 A}$

(C) Faculty of Mechanical Engineering, Belgrade. All rights reserved that define the boundaries of PDFs assigned to them. For the case of a two-resistor divider with uniformly distributed resistances, an expression for the PDF of the divider's voltage transfer ratio is derived analytically and compared to plots produced by numerical (Monte Carlo) simulations. For normally distributed resistances, analytical approach becomes cumbersome, wherefore analysis of these circuits relies on simulations to plot voltage ratio PDFs and calculate the values of its parameters.

Investigation conducted in this paper is akin to statistical tolerance analysis and propagation of uncertainty in measurement. Voltage divider ratios are studied using both statistical methods of random sampling and the theoretical approach of probability theory.

\section{PROBABILISTIC TREATMENT OF RESISTOR TOLERANCE MAIN HEADING}

The tolerance of a resistor expresses the maximum deviation of its resistance from a nominal value. This deviation is stochastic, and therefore the resistance can be treated as a random quantity, with a PDF that has nonzero values within an interval defined by the tolerance. This interval encompasses the nominal value, and its bounds are obtained from percentage tolerance, which has the meaning of maximum relative uncertainty with regard to the nominal value $[2,3,4,5]$.

If no additional information is available as to how the possible values of resistance are expected to be distributed inside the said interval, random resistance is assigned a uniform distribution, centred on the nominal value, with a half-width equal to the maximum relative uncertainty multiplied by the nominal value. Uniform distribution expresses equal probability for the resistance to take any single value from the tolerance interval. Denoting the nominal resistance $R_{0}$, and the resistor 
tolerance (i.e. maximum relative uncertainty) $\Delta R / R_{0}$, resistance $\mathrm{R}$ has a uniform distribution $\left(R \sim \operatorname{Unif}\left(R_{0}-\right.\right.$ $\left.\Delta R, R_{0}+\Delta R\right)$ ) with a $\operatorname{PDF} f_{R}$ equal to:

$$
f_{R}=\left\{\begin{array}{cc}
\frac{1}{2 \Delta R} & R \in\left[R_{0}-\Delta R, R_{0}+\Delta R\right] \\
0 & R \notin\left[R_{0}-\Delta R, R_{0}+\Delta R\right]
\end{array}\right.
$$

If the lower and the upper bound of resistance are renamed $R^{\prime}=R_{0}-\Delta R$ and $R^{\prime \prime}=R_{0}+\Delta R$, the distribution is $R \sim \operatorname{Unif}\left(R^{\prime}, R^{\prime \prime}\right)$ and its PDF:

$$
f_{R}=\left\{\begin{array}{cc}
\frac{1}{R^{\prime \prime}-R^{\prime}} & R \in\left[R^{\prime}, R^{\prime \prime}\right] \\
0 & R \notin\left[R^{\prime}, R^{\prime \prime}\right]
\end{array}\right.
$$

A different approach would be to assign a normal (Gaussian) distribution to the resistor, centered around the nominal resistance $R_{0}$, with $\Delta R$ equal to triple standard uncertainty. In this case, resistance PDF is:

$$
f_{R}=\frac{1}{\Delta R \sqrt{2 \pi} / 3} e^{-\frac{\left(R-R_{0}\right)^{2}}{2(\Delta R / 3)^{2}}}
$$

In order to bound possible values of resistance to a finite range, with lower and upper bounds being $R^{\prime}=R_{0}$ $-\Delta R$ and $R^{\prime \prime}=R_{0}+\Delta R$, respectively, the so called truncated normal distribution is often used $[1,6,7]$. The PDF for the truncated distribution has to be renormalized over the $\left[R^{\prime}, R^{\prime \prime}\right]$ range. With $\Delta R$ still equal to triple standard uncertainty, this is accomplished by dividing the right-hand side of equation (3) by:

$$
\Phi\left(\frac{R^{\prime \prime}-R_{0}}{\Delta R / 3}\right)-\Phi\left(\frac{R^{\prime}-R_{0}}{\Delta R / 3}\right)
$$

where $\Phi(x)$ is the standard normal cumulative distribution function (CDF):

$$
\Phi(x)=\frac{1}{\sqrt{2 \pi}} \int_{-\infty}^{x} e^{-\frac{t^{2}}{2}} d t .
$$

After expressions for $R^{\prime}$ and $R^{\prime \prime}$ are inserted into (5) it becomes $\Phi(3)-\Phi(-3) \approx 0.9973$. The PDF of the resistance distributed according to the truncated normal distribution is:

$$
f_{R}=\left\{\begin{array}{c}
\frac{1.0027}{\Delta R \sqrt{2 \pi} / 3} e^{-\frac{\left(R-R_{0}\right)^{2}}{2(\Delta R / 3)^{2}}} R \in\left[R_{0}-\Delta R, R_{0}+\Delta R\right] \\
0 \quad R \notin\left[R_{0}-\Delta R, R_{0}+\Delta R\right]
\end{array}\right.
$$

If a random variable $X$ follows the truncated normal distribution we write $X \sim \mathrm{TN}\left(\mu, \sigma^{2}, a, b\right)$, where $\mu$ and $\sigma$ are the expectation value and standard deviations of the original normal distribution, while $a$ and $b$ are the bounds of the range it is truncated to. For resistance, this becomes $R \sim \mathrm{TN}\left(R_{0},(\Delta R / 3)^{2}, R^{\prime}, R^{\prime \prime}\right)$, where $\Delta R=3 \sigma$ is assumed [20,21].
Considerations in this paper disregard resistance temperature drift, another important property commonly stated by resistor manufacturers. The whole analysis is performed under the assumption that the temperature of the resistor, resulting from self-heating and thermal interaction with environment, is constant for the time interval of interest.

\section{THEORETICAL PDF OF A TWO-RESISTOR VOL- TAGE DIVIDER RATIO}

There are many roles that a voltage divider can assume in a larger electronic circuit. The most common use of a divider is for attenuating a voltage by a desired ratio. Another widespread use of voltage dividers is for arms in quarter-, half- and full-bridges, in which case at least one resistor in one of the two arms of the bridge is a sensor (e.g. a strain gauge, piezoresistor, thermoresistive sensor or photoresistor). Nominal values of the resistors in a bridge are usually set equal, for the purposes of maximum measuring sensitivity and temperature compensation. At the very least, the voltage ratios of the two arms in a bridge need to be equal for the bridge to be balanced and provide zero output voltage at zero value of the measured quantity. In the most general case, however, the two resistors in a divider differ in both nominal value and tolerance $[1,2]$.

A scheme of a two-resistor voltage divider is shown in figure 1. Either a DC or an AC input voltage can be fed to the divider. The parameter characterizing a voltage divider circuit is the voltage ratio, defined as the output-to-input voltage ratio $\alpha=v_{o} / v_{i}$. If the input voltage is assumed to be obtained from an ideal voltage source, with negligible internal resistance, voltage ratio for a two-resistor divider is:

$$
\alpha=\frac{R_{1}}{R_{1}+R_{2}}
$$

Expression (7) is a non-linear circuit function, dependent on two input quantities, namely the two resistances. It is strictly valid only when the divider is not loaded by other circuits connected to its output terminals. This is practically achieved by making the output resistance of the divider $R_{\text {out }}=R_{1} R_{2} /\left(R_{1}+R_{2}\right)$ significantly lower than the input resistance of the next stage circuit. If the next stage input resistance is comparable to $R_{\text {out }}$, for the purposes of the present analysis it will suffice to assume that its effect is included in both the nominal resistance and tolerance of resistor $R_{l}$.

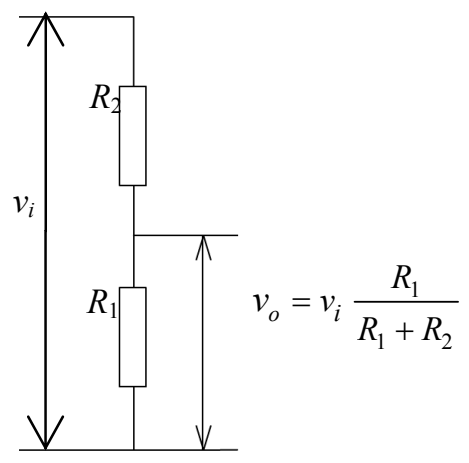

Figure 1. Scheme of a two-resistor voltage divider 
Following considerations in section 2, resistors in the voltage divider presented in figure 1 can be assigned either uniform distributions $R_{1} \sim \operatorname{Unif}\left(R_{1}^{\prime}, R_{1}{ }^{\prime \prime}\right)$ and $R_{2} \sim$ $\operatorname{Unif}\left(R_{2}{ }^{\prime}, R_{2}{ }^{\prime \prime}\right)$, or truncated normal distributions $R_{1} \sim \mathrm{TN}$ $\left(R_{01},\left(\Delta R_{1} / 3\right)^{2}, R_{1}^{\prime}, R_{1}^{\prime \prime}\right)$ and $R_{2} \sim \mathrm{TN}\left(R_{02},\left(\Delta R_{2} / 3\right)^{2}, R_{2}^{\prime}\right.$, $\left.R_{2}^{\prime \prime}\right)$.

Let us first examine the denominator of expression (3) for these two cases. PDF of the sum of two independent random variables is found as a convolution of their PDFs. For independent uniformly distributed resistances $R_{1}$ and $R_{2}$, their sum $R_{1}+R_{2}$ has either a trapezoidal or a triangular PDF, depending on the widths of the two uniform distributions [1]. The sum of two independent normally distributed resistances $R_{1} \sim$ $\mathrm{N}\left(R_{01},\left(\Delta R_{1} / 3\right)^{2}\right)$ and $R_{2} \sim \mathrm{N}\left(R_{02},\left(\Delta R_{2} / 3\right)^{2}\right)$ is also a normal random variable $\left(R_{1}+R_{2}\right) \sim \mathrm{N}\left(R_{01}+R_{02}\right.$, $\left.\left(\Delta R_{1} / 3\right)^{2}+\left(\Delta R_{2} / 3\right)^{2}\right)$.

For uniformly distributed resistances, PDF of the voltage divider ratio $\alpha$ can be derived analytically in the following manner. An auxiliary variable $\beta$ is introduced as $\beta=R_{2}$, so that there is a scalar function relating random vectors $\left(R_{1}, R_{2}\right)$ and $(\alpha, \beta)$, defined by the equations:

$$
\begin{gathered}
\mathrm{R}_{1}=\frac{\alpha \beta}{1-\alpha} \\
\mathrm{R}_{2}=\beta
\end{gathered}
$$

The PDFs of $R_{1}$ and $R_{2}$ are:

$$
\begin{aligned}
& \mathrm{f}_{\mathrm{R}_{1}}=\left\{\begin{array}{cc}
\frac{1}{\mathrm{R}_{1}{ }^{\prime}-\mathrm{R}_{1}^{\prime}} & \mathrm{R}_{1} \in\left[\mathrm{R}_{1}^{\prime}, \mathrm{R}_{1}{ }^{\prime}\right] \\
0 & \mathrm{R}_{1} \notin\left[\mathrm{R}_{1}^{\prime}, \mathrm{R}_{1}^{\prime \prime}\right]
\end{array}\right. \\
& f_{R_{2}}=\left\{\begin{array}{cc}
\frac{1}{R_{2}{ }^{\prime}-R_{2}^{\prime}} & R_{2} \in\left[R_{2}^{\prime}, R_{2}^{\prime}\right] \\
0 & R_{2} \notin\left[R_{2}^{\prime}, R_{2}^{\prime}\right]
\end{array}\right.
\end{aligned}
$$

where $R_{1}{ }^{\prime}, R_{1}{ }^{\prime \prime}, R_{2}{ }^{\prime}$ and $R_{2}{ }^{\prime \prime}$ are all positive.

Assuming that resistances $R_{1}$ and $R_{2}$ are independent, the joint (bivariate) PDF of the $\left(R_{1}, R_{2}\right)$ vector is equal to the product of marginal PDFs $f_{R 1}$ and $f_{R 2}$ given by equations (10) and (11):

$$
\begin{aligned}
& f_{\left(R_{1}, R_{2}\right)}=f_{R_{1}} \cdot f_{R_{2}}=\frac{1}{\left(R_{1}^{\prime}-R_{1}^{\prime}\right)\left(R_{2}^{\prime}-R_{2}^{\prime}\right)}, \\
& R_{1} \in\left[R_{1}^{\prime}, R_{1}^{\prime}\right], R_{2} \in\left[R_{2}^{\prime}, R_{2}^{\prime}\right]
\end{aligned}
$$

The support of the joint PDF, i.e. the subregion of the $R_{1}-R_{2}$ domain where the function is not zero-valued, is indicated in equation (12).

Probability that the value of the random vector $\left(R_{1}\right.$, $R_{2}$ ) falls within an elementary area $d R_{1} d R_{2}$ in the $R_{1}-R_{2}$ domain is equal to the probability that the value of the random vector $(\alpha, \beta)$ is within a corresponding elementary area $d \alpha d \beta$ in the $\alpha-\beta$ domain. When switching from one set of coordinates to another, elementary areas in the two domains are related through the Jacobian determinant as:

$$
\mathrm{dR}_{1} \mathrm{dR}_{2}=|J| \mathrm{d} \alpha \mathrm{d} \beta
$$

where

$$
|J|=\left|\begin{array}{cc}
\frac{\partial R_{1}}{\partial \alpha} & \frac{\partial R_{1}}{\partial \beta} \\
\frac{\partial R_{2}}{\partial \alpha} & \frac{\partial R_{2}}{\partial \beta}
\end{array}\right|=\left|\begin{array}{cc}
\frac{\beta}{(1-\alpha)^{2}} & \frac{\alpha}{1-\alpha} \\
0 & 1
\end{array}\right|=\frac{\beta}{(1-\alpha)^{2}}
$$

The said equality of probabilities, expressed through joint probability densities of the two random vectors, gives:

$$
f_{(\alpha, \beta)} d \alpha d \beta=f_{\left(R_{1}, R_{2}\right)} d R_{1} d R_{2}
$$

Using equations (12), (14), and (15), the joint PDF of the $(\alpha, \beta)$ vector is obtained as:

$$
f_{(\alpha, \beta)}=\frac{1}{\left(\mathrm{R}_{1}{ }^{\prime}-\mathrm{R}_{1}{ }^{\prime}\right)\left(\mathrm{R}_{2}{ }^{\prime}-\mathrm{R}_{2}{ }^{\prime}\right)} \frac{1}{(1-\alpha)^{2}} \beta
$$

The support of this joint PDF, i.e. the subregion of the $\alpha-\beta$ domain where $f_{(\alpha, \beta)} \neq 0$, is defined by the following intervals:

$$
\begin{gathered}
\alpha \in\left[\frac{\mathrm{R}_{1}{ }^{\prime}}{\mathrm{R}_{1}{ }^{\prime}+\mathrm{R}_{2}{ }^{\prime}}, \frac{\mathrm{R}_{1}{ }^{\prime \prime}}{\mathrm{R}_{1}{ }^{\prime}+\mathrm{R}_{2}{ }^{\prime}}\right] \\
\beta \in\left[\mathrm{R}_{2}{ }^{\prime}, \mathrm{R}_{2}{ }^{\prime}\right] \\
\mathrm{R}_{1} \in\left[\mathrm{R}_{1}{ }^{\prime}, \mathrm{R}_{1}^{\prime}\right]
\end{gathered}
$$

The minimum and maximum values of $\alpha$ in expression (17) can be obtained by inserting the limiting values of $R_{1}$ and $R_{2}$ into relation (7), considering that these limits $\left(R_{1}{ }^{\prime}, R_{1}{ }^{\prime}, R_{2}{ }^{\prime}\right.$ and $\left.R_{2}{ }^{\prime \prime}\right)$ are all positive. The strict derivation that follows will shortly yield the same result for these limits. Using equation (8), the range in relation (19) produces another interval that $\beta$ has to be in for $f_{(\alpha, \beta)}$ to be non-zero:

$$
\beta \in\left[\mathrm{R}_{1}^{\prime}\left(\frac{1}{\alpha}-1\right), \mathrm{R}_{1}^{\prime \prime}\left(\frac{1}{\alpha}-1\right)\right]
$$

The marginal PDF of the voltage ratio $\mathrm{f} \alpha$ is obtained by integrating the joint PDF $\mathrm{f}_{(\alpha, \beta)}$ with respect to $\beta$ over all possible values, i.e. from $-\infty$ to $+\infty$ :

$$
f_{\alpha}=\int_{-\infty}^{+\infty} f_{(\alpha, \beta)} \mathrm{d} \beta
$$

The solution of this definite integral depends on the limiting values of $\beta$ for which $f(\alpha, \beta)$ is non-zero, which again, according to relation (20), depend also on $\alpha$. This means that $\mathrm{f} \alpha$ is different for various ranges of $\alpha$. $\beta$ has to satisfy both (18) and (20) for $f_{(\alpha, \beta)}$ to be non-zero. Which of these two intervals imposes a more stringent limit on the lower or upper bound of $\beta$ depends on the value of $\alpha$. The two ranges of $\beta$ are presented on the $\beta$-versus- $\alpha$ graphs in figure 2 . Limits expressed by (18) are shown as horizontal lines at $\beta=R_{2}{ }^{\prime}$ and $\beta=R_{2}{ }^{\prime \prime}$, while the limits in (20) are the two hyperbolas $\beta=R_{l}{ }^{\prime}(1 / \alpha-1)$ and $\beta=R_{l}{ }^{\prime}(1 / \alpha-1)$. The upper and lower bounds to be used in the solution of integral (21) can now be deduced from the graph.

The minimum possible vsalue of $\alpha$, below which $f_{(\alpha, \beta)}$ is zero, corresponds to the intersection of curves $\beta=$ $R_{2}^{\prime \prime}$ and $\beta=R_{l}{ }^{\prime}(1 / \alpha-1)$, which gives $\alpha_{\text {min }}=R_{l}{ }^{\prime} /\left(R_{l}{ }^{\prime}+\right.$ $\left.R_{2}{ }^{\prime \prime}\right)$. For values of $\alpha$ lower than this the two intervals of 


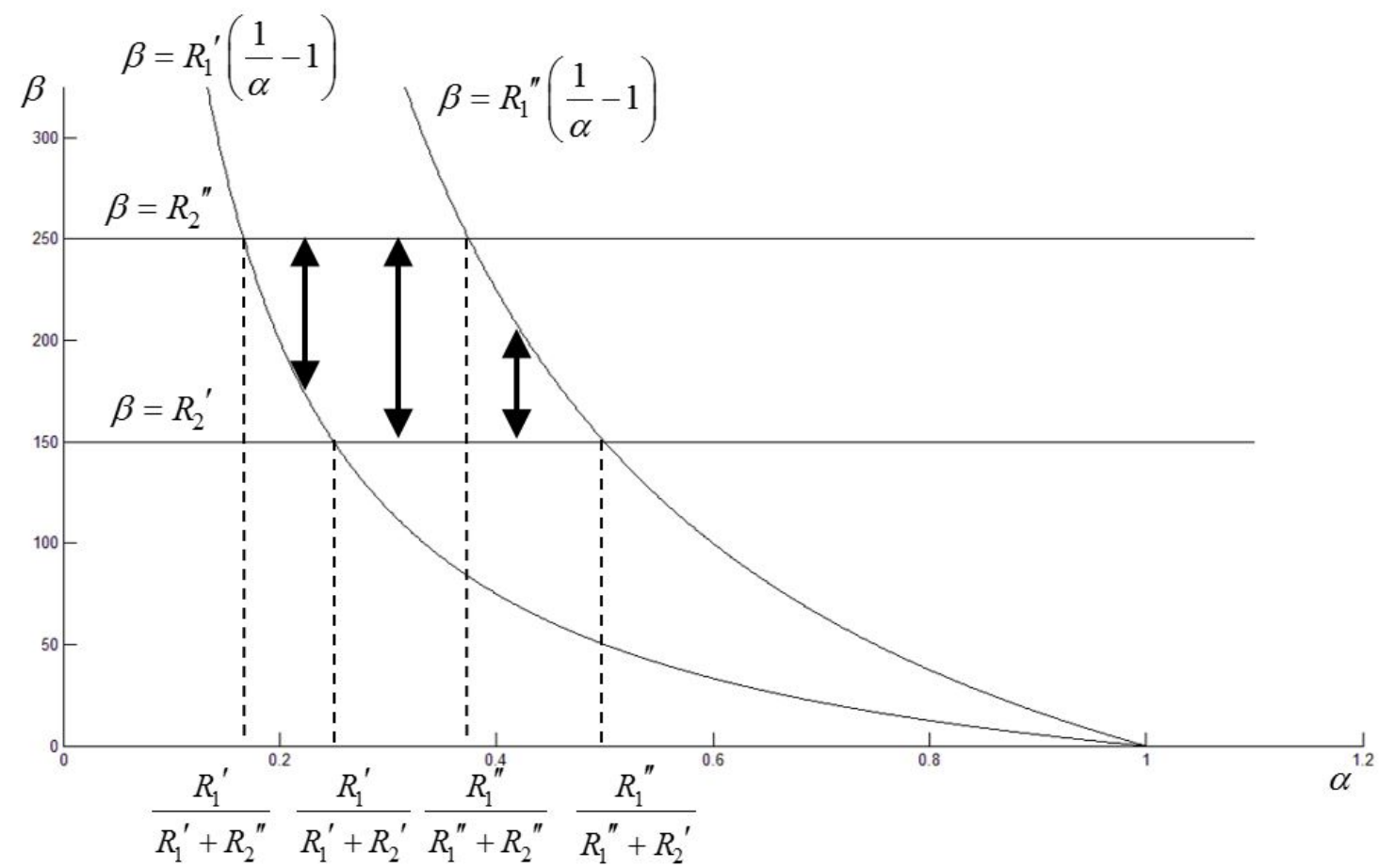

a)

a)

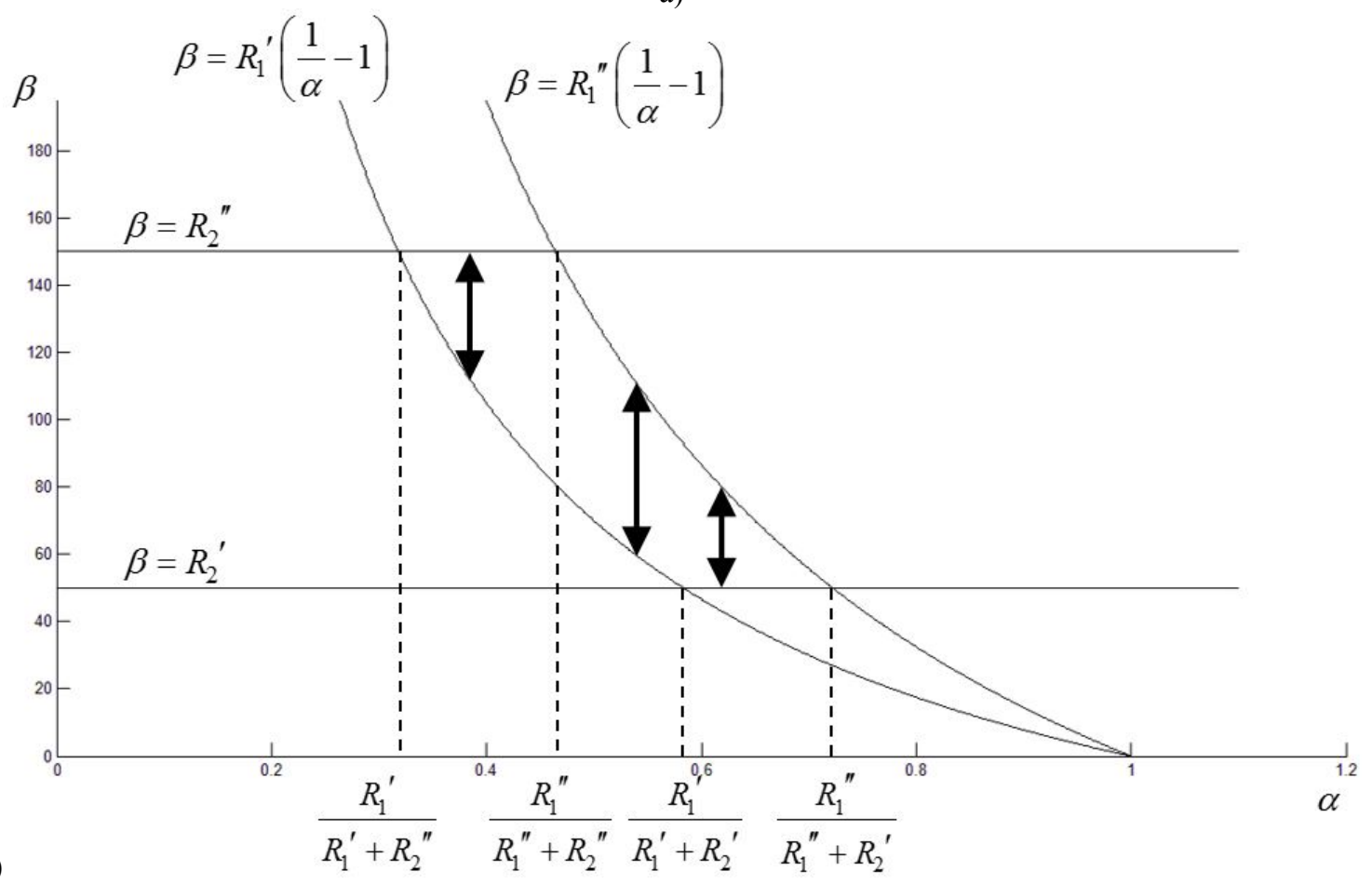

b)

Figure 2. Graphs showing the limiting values of $\beta$ for which $f_{(\alpha, \beta)}$ is non-zero in various ranges of $\alpha$, for the two distinct cases:

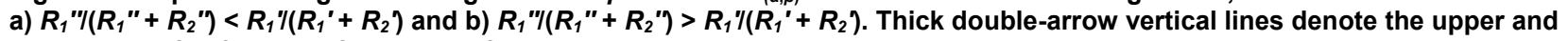
lower bound for $\beta$ in specific ranges of $\alpha$.

$\beta$ do not overlap, the upper bound of one is lower than the lower bound of the other, and hence $f_{(\alpha, \beta)}=0$. By the same reasoning, maximum value of $\alpha$ above which $f_{(\alpha, \beta)}=0$ is at the section of curves $\beta=R_{2}{ }^{\prime}$ and $\beta=$ $R_{l}^{\prime \prime}(1 / \alpha-1)$, which yields $\alpha_{\max }=R_{l}^{\prime \prime} /\left(R_{l}^{\prime \prime}+R_{2}{ }^{\prime}\right)$.

There are two distinct cases that may arise, one for which $R_{I}{ }^{\prime \prime} /\left(R_{I}^{\prime \prime}+R_{2}{ }^{\prime \prime}\right)<R_{I}{ }^{\prime} /\left(R_{I}{ }^{\prime}+R_{2}{ }^{\prime}\right)$, shown in figure 2.a), and another for which the opposite holds, presented in figure 2.b). In each case, the solution of integral (21) has five different formats in five adjacent ranges of $\alpha$. A general solution to (21) is:

$$
f_{\alpha}=\left.\frac{1}{2\left(R_{1}^{\prime}-R_{1}^{\prime}\right)\left(R_{2}^{\prime}-R_{2}^{\prime}\right)} \frac{1}{(1-\alpha)^{2}} \beta^{2}\right|_{\beta \text { lower }} ^{\beta_{\text {upper }}}
$$

where $\beta_{\text {upper }}$ and $\beta_{\text {lower }}$ are the upper and lower bound for $\beta$ in any specific range of $\alpha$, denoted by thick double-arrow vertical lines in figures 2.a) and 2.b).

The final solution for the PDF of $\alpha$ when resistances are uniformly distributed becomes (23). 


$$
f_{\alpha}=\frac{1}{2\left(R_{1}^{\prime}-R_{1}^{\prime}\right)\left(R_{2}^{\prime}-R_{2}^{\prime}\right)} \frac{1}{(1-\alpha)^{2}} \cdot\left\{\begin{array}{cc}
\alpha \in 0, \frac{R_{1}^{\prime}}{R_{1}^{\prime}+R_{2}^{\prime}} \\
\left(R_{2}^{\prime}\right)^{2}-\left(R_{1}^{\prime}\right)^{2}\left(\frac{1}{\alpha}-1\right)^{2} & \alpha \in\left[\frac{R_{1}^{\prime}}{R_{1}^{\prime}+R_{2}^{\prime}}, \min \left(\frac{R_{1}^{\prime}}{R_{1}^{\prime}+R_{2}^{\prime}}, \frac{R_{1}^{\prime}}{R_{1}^{\prime}+R_{2}^{\prime}}\right)\right] \\
\left.\left(R_{1}^{\prime}\right)^{2}-\left(R_{1}^{\prime}\right)^{2}\right)\left(\frac{1}{\alpha}-1\right)^{2} & \alpha \in\left[\frac{R_{1}^{\prime}}{R_{1}^{\prime}+R_{2}^{\prime \prime}}, \frac{R_{1}^{\prime}}{R_{1}^{\prime}+R_{2}^{\prime}}\right], \text { if } \frac{R_{1}^{\prime}}{R_{1}^{\prime}+R_{2}^{\prime}}<\frac{R_{1}^{\prime}}{R_{1}^{\prime}+R_{2}^{\prime}} \\
\left(R_{2}^{\prime}\right)^{2}-\left(R_{2}^{\prime}\right)^{2} & \alpha \in\left[\frac{R_{1}^{\prime}}{R_{1}^{\prime}+R_{2}^{\prime}}, \frac{R_{1}^{\prime}}{R_{1}^{\prime}+R_{2}^{\prime}}\right], \text { if } \frac{R_{1}^{\prime}}{R_{1}^{\prime \prime}+R_{2}^{\prime}}>\frac{R_{1}^{\prime}}{R_{1}^{\prime}+R_{2}^{\prime}} \\
\left(R_{1}^{\prime}\right)^{2}\left(\frac{1}{\alpha}-1\right)^{2}-\left(R_{2}^{\prime}\right)^{2} & \alpha \in\left[\max \left(\frac{R_{1}^{\prime}}{R_{1}^{\prime}+R_{2}^{\prime}}, \frac{R_{1}^{\prime}}{R_{1}^{\prime}+R_{2}^{\prime}}\right), \frac{R_{1}^{\prime}}{R_{1}^{\prime}+R_{2}^{\prime}}\right] \\
0 & \left.\alpha \in \frac{R_{1}^{\prime}}{R_{1}^{\prime}+R_{2}^{\prime}}, 1\right)
\end{array}\right.
$$

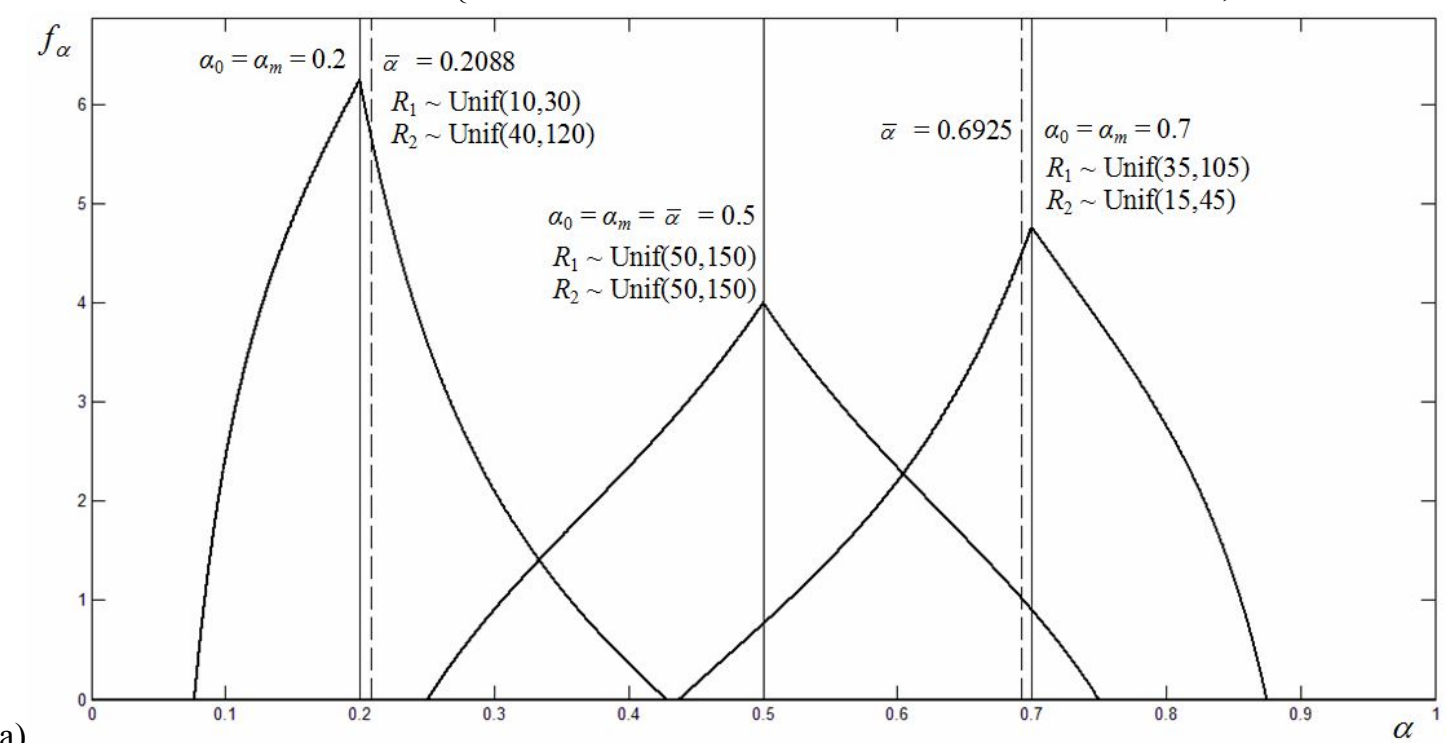

a)

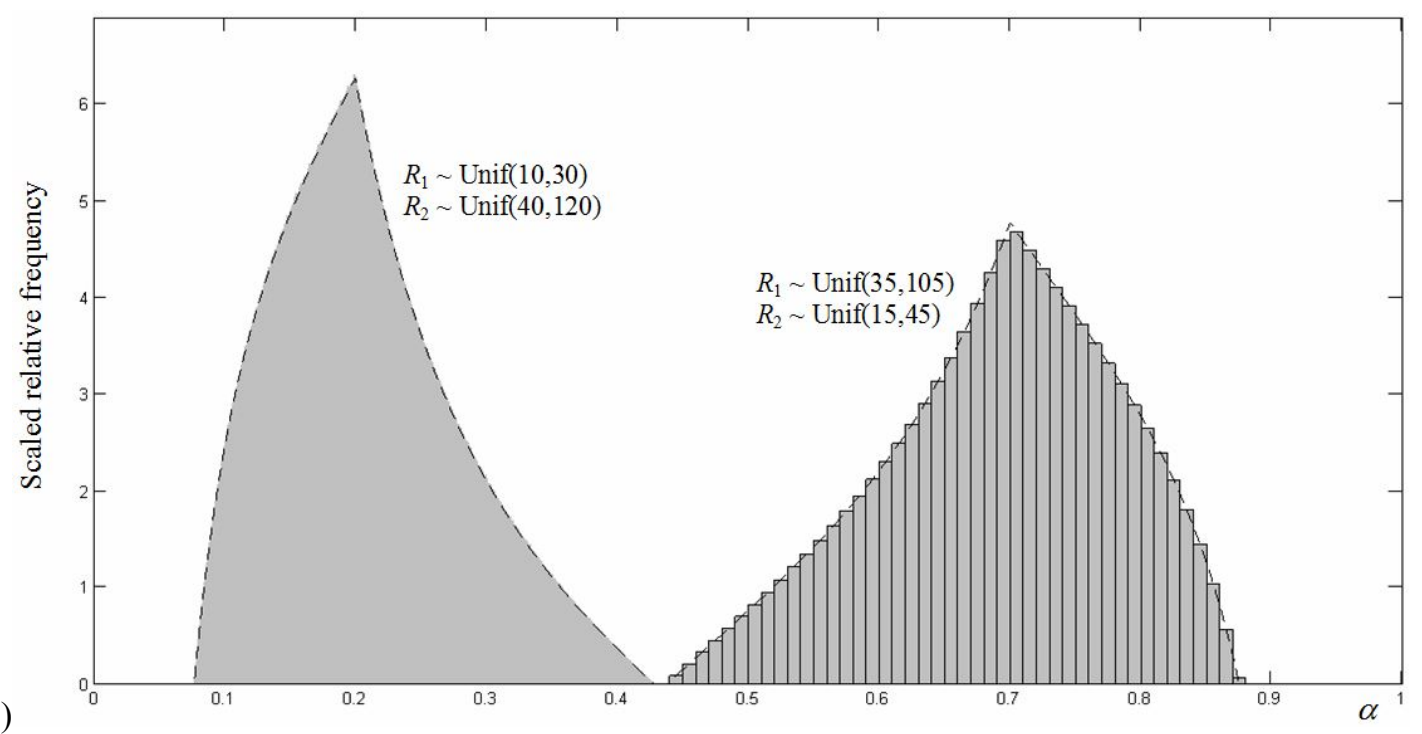

Figure 3. Plots for dividers whose resistors have equal tolerances and uniformly distributed resistances.

a) Volage ratio PDFs detemined from the analytical expression (23) for dividers with $\Delta R_{1} / R_{01}=\Delta R_{2} / R_{02}=50 \%$. The central plot is for a divider with $R_{01}=R_{02}=100 \Omega$ (nominal ratio of $\alpha_{0}=0.5$ ), the left plot for $R_{01}=20 \Omega, R_{02}=80 \Omega\left(\alpha_{0}=0.2\right.$ ), and the right ne for $\boldsymbol{R}_{01}=70 \Omega, \boldsymbol{R}_{02}=30 \Omega\left(\alpha_{0}=0.7\right)$. Nominal $\left(\alpha_{0}\right)$ and mean $(\bar{\alpha})$ value of the voltage ratio for each divider are indicated by the solid and dashed vertical lines, respectively. Dotted vertical lines that correspond to most probable values $\left(\alpha_{m}\right)$ are not visible because they overlap with solid lines representing the $\alpha_{0}$ values.

b) Scaled relative frequency histograms of voltage ratio values for the previously considered dividers with $\alpha_{0}=0.2$ and $\alpha_{0}=$ 0.7, determined by the Monte Carlo method with 108 trials. Bin sizes are 0.0001 and 0.01 for the left and the right histogram, respectively. Voltage ratio PDFs are approximated by the envelopes of the histograms. Analytical PDF curves for the two dividers are shown as dashed plots. 
When $X$ and $Y$ are random variables with zero-mean normal distributions, their ratio $\mathrm{X} / \mathrm{Y}$ has a Cauchy distribution $[8,9,10,11]$. However, when the two normal distributions have non-zero means, as in the case of normally distributed divider resistances, distribution of the ratio is much more complicated $[12,13,14]$. It is therefore more convenient to use numerical simulation in this case, assuming that resistances have truncated normal distributions $[15,16,17,18,19]$.

\section{PLOTS FOR A DIVIDER WITH UNIFORMLY DISTRIBUTED RESISTANCES}

Various cases of a two-resistor divider with uniformly distributed resistances are distinguished by the nominal resistances and the associated tolerances (maximum relative uncertainties). Both the nominal resistances of the two resistors and their tolerances can either be equal or different, with one being larger or smaller than the other.

Plots in figure 3.a) present voltage ratio PDFs determined from the analytical expression (23) for dividers whose resistors have equal tolerances $\Delta R_{1} / R_{01}=$ $\Delta R_{2} / R_{02}=50 \%$. The tolerances have been purposely exaggerated, compared to typical resistor tolerances found in practice $(\sim 1 \%)$, to make the effect of the circuit function's non-linearity (equation (7)) on the shape of the voltage ratio's PDF visible. The central plot is for a divider with $R_{01}=R_{02}=100 \Omega$ (i.e. nominal ratio of $\alpha_{0}=$ $0.5)$, the left plot for $R_{01}=20 \Omega, R_{02}=80 \Omega\left(\alpha_{0}=0.2\right)$, and the right one for $R_{01}=70 \Omega, R_{02}=30 \Omega\left(\alpha_{0}=0.7\right)$. Nominal $\left(\alpha_{0}\right)$, mean $(\bar{a})$ and most probable $\left(\alpha_{m}\right)$ value of the voltage ratio for each divider, calculated numerically from expression (23), are indicated by the solid, dashed, and dotted vertical lines, respectively.

For a divider with equal resistances and equal tolerances (central plot in figure 3.a) the PDF of the ratio is symmetrical around the 0.5 value. Nominal, mean and most probable value of the ratio all coincide $\left(\alpha_{0}=\bar{\alpha}=\right.$ $\left.\alpha_{m}=0.5\right)$. The PDF has a shape of a curvilinear triangle, with sides that have one inflection point each. Dividers with nominal ratios other than 0.5 (side plots in figure 3.a) have markedly asymmetrical voltage ratio PDFs, which results in a deviation of the mean value of the ratio from $\alpha_{0}$. In all three cases, however, PDFs are shaped as curvilinear triangles, with $\alpha_{0}=\alpha_{m}$. Dotted vertical lines that correspond to values of $\alpha_{\mathrm{m}}$ are not visible because they overlap with solid lines representing the $\alpha_{0}$ values. The equality of resistor tolerances $\left(\Delta R_{1} / R_{01}=\Delta R_{2} / R_{02}\right)$ gives:

$$
\frac{\frac{\mathrm{R}_{1}{ }^{\prime}-\mathrm{R}_{1}{ }^{\prime}}{2}}{\frac{\mathrm{R}_{1}{ }^{\prime}+\mathrm{R}_{1}{ }^{\prime \prime}}{2}}=\frac{\frac{\mathrm{R}_{2}{ }^{\prime}-\mathrm{R}_{2}{ }^{\prime}}{2}}{\frac{\mathrm{R}_{2}{ }^{\prime}+\mathrm{R}_{2}{ }^{\prime \prime}}{2}}
$$

which reduces to:

$$
\frac{\mathrm{R}_{2}{ }^{\prime}}{\mathrm{R}_{1}{ }^{\prime}}=\frac{\mathrm{R}_{2}{ }^{\prime}}{\mathrm{R}_{1}{ }^{\prime}}
$$

wherefrom:

$$
\frac{\mathrm{R}_{1}{ }^{\prime}}{\mathrm{R}_{1}{ }^{\prime}+\mathrm{R}_{2}{ }^{\prime}}=\frac{\mathrm{R}_{1}{ }^{\prime \prime}}{\mathrm{R}_{1}{ }^{\prime}+\mathrm{R}_{2}{ }^{\prime \prime}}
$$

Equation (26) shows that the limits of the central region in expression (23) are equal, which means that this segment of $f_{\alpha}$ is missing, and this makes the PDFs curved-triangle.

Histograms of voltage ratio values for the previously considered dividers with $\alpha_{0}=0.2$ and $\alpha_{0}=0.7$, determined by the Monte Carlo method (MCM), are shown in figure 3.b). MCM is a numerical simulation that uses randomly generated values of resistances to calculate the value of the voltage ratio. Values are repeatedly sampled from corresponding distributions, which in this case are uniform distributions over the intervals determined by resistor tolerances $\left(R_{1} \sim\right.$ $\operatorname{Unif}\left(R_{01}-\Delta R_{1}, R_{01}+\Delta R_{1}\right), R_{2} \sim \operatorname{Unif}\left(R_{02}-\Delta R_{2}, R_{02}+\right.$ $\left.\Delta R_{2}\right)$ ).

In each trial, values of $R_{1}$ and $R_{2}$ are sampled independently, and the value of $\alpha$ calculated according to equation (7). The obtained values of the ratio are then tallied into a histogram with a specified interval width (i.e. bin size). For comparison with PDF plots, scaled relative frequency histograms are used, in which bar hight over each bin is obtained by dividing the relative frequency of that bin by the bin size. This kind of histogram is also known as the relative frequency density histogram. The total area of a scaled relative frequency histogram is unity.

Histograms in figure 3.b) have each been produced with 108 trials. Voltage ratio PDFs are approximated by the envelopes of the histograms. The bin size of the left histogram is 0.0001 . For the number of trials this high, and for bins this narrow, the histogram appears smooth and its envelope is easy to observe. Thin histogram bars cannot be delineated separately and instead form a joint gray area.

To illustrate the discrete nature of histograms, a larger bin size of 0.01 has been chosen for the one on the right. This has resulted in a ragged upper edge of the histogram, which nevertheless gives a good idea about the shape of the PDF. Analytical PDF curves for the two dividers are shown again as dashed plots in figure 3.b). It is evident that there is excellent agreement between analytical plots and histogram envelopes.

Plots in figure 4.a) show voltage ratio PDFs obtained from expression (23) for dividers whose resistor tolerances differ. Nominal resistances, and therefore also nominal voltage ratios, are the same as for the three dividers in figure 3.a) $\left(\alpha_{0}\right.$ is $0.2,0.5$ and 0.7 from left to right). The left plot is for a divider with $R_{01}=20 \Omega, R 0_{2}=80 \Omega, \Delta R_{1} / R_{01}=25 \%$, and $\Delta R_{2} / R_{02}=50 \%$. The central plot is for $R_{01}=R_{02}=100$ $\Omega, \Delta R_{1} / R_{01}=50 \%$, and $\Delta R_{2} / R_{02}=30 \%$. The right plot is for $R_{01}=70 \Omega, R_{02}=30 \Omega, \Delta R_{1} / R_{01} \approx 14.3 \%$, and $\Delta R_{2} / R_{02}=50 \%$. Since equality (26) no longer holds, each of these PDFs has all five segments predicted by expression (23). Voltage ratio PDFs are all shaped as irregular curvilinear quadrilaterals, with marked asymmetry which stems from the non-linearity of the circuit function. The asymmetry of the PDFs gives rise to differences between nominal, mean and most probable values of the voltage ratio in all three dividers. The tolerances have again been exaggerated on purpose, to make the divergence of and $\alpha_{m}$ from $\alpha_{0}$ visible. 


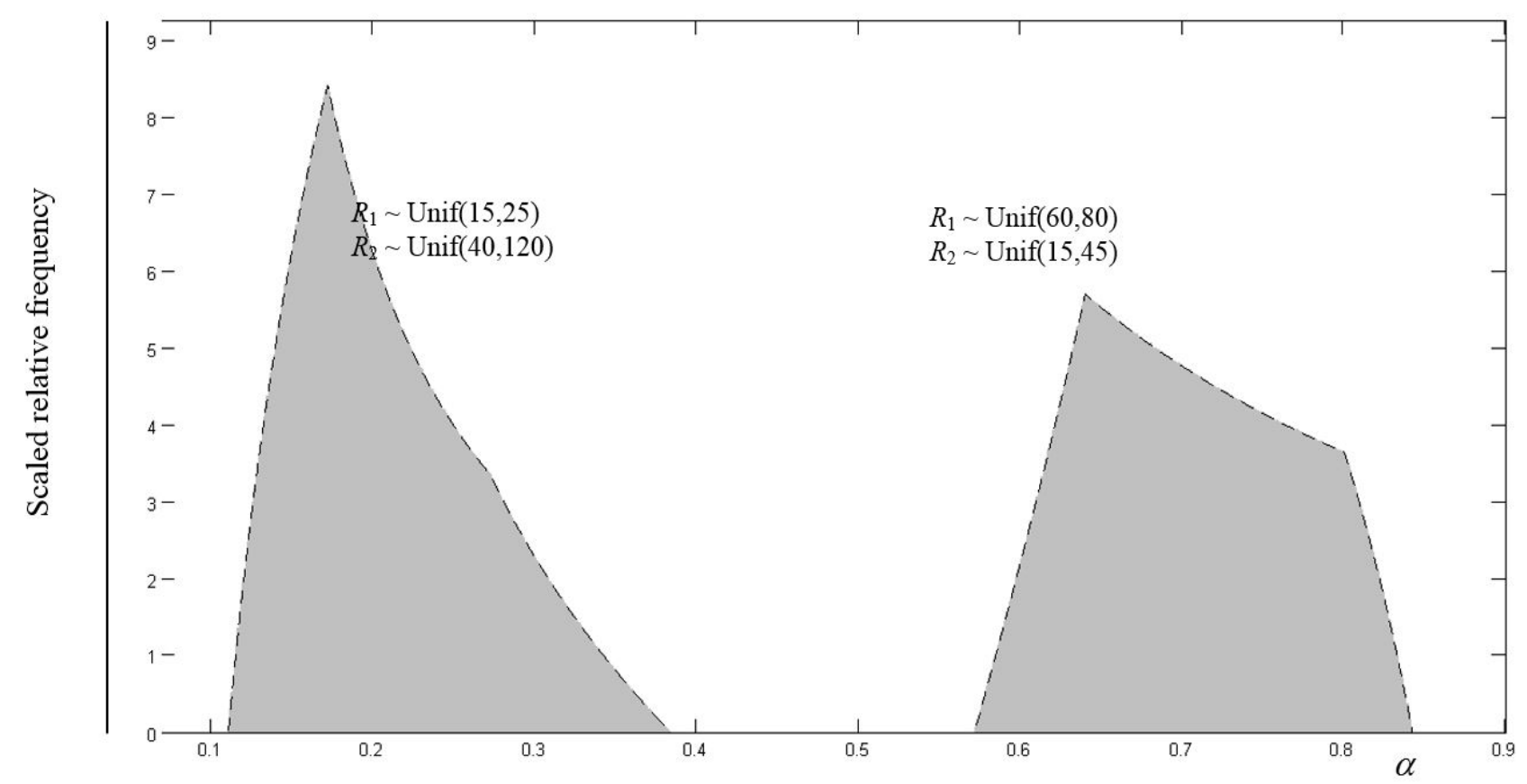

a)

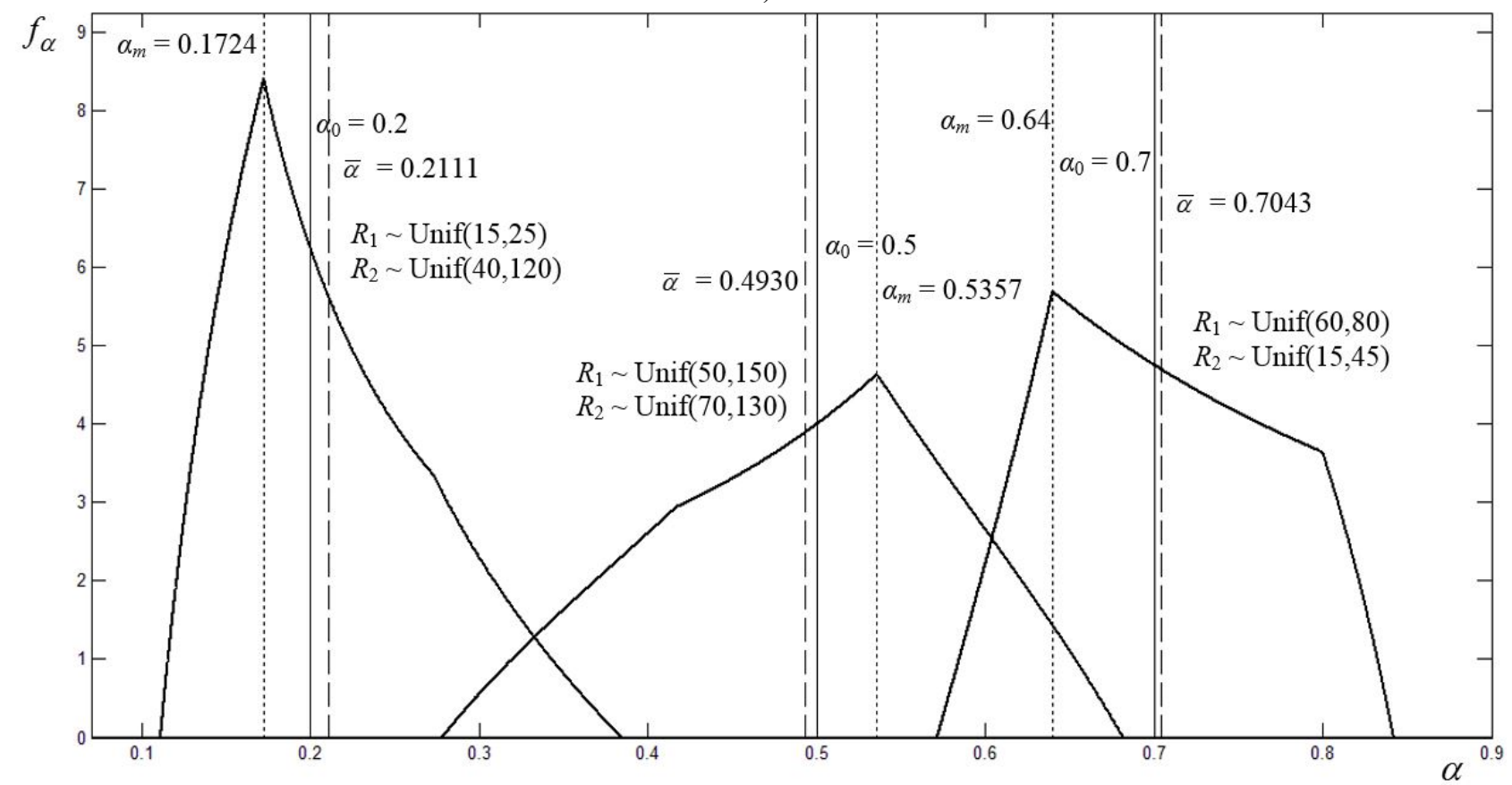

b)

Figure 4. Plots for dividers whose resistors have different tolerances and uniformly distributed resistances.

a) Voltage ratio PDFs determined from the analytical expression (23). The left plot is for a divider with $R_{01}=20 \Omega, R_{02}=80 \Omega\left(\alpha_{0}\right.$ $=0.2), \Delta R_{1} / R_{01}=25 \%, \Delta R_{2} / R_{02}=50 \%$. The central plot is for $R_{01}=R_{02}=100 \Omega\left(\alpha_{0}=0.5\right), \Delta R_{1} / R_{01}=50 \%, \Delta R_{2} / R_{02}=30 \%$. The right plot is for $R_{01}=70 \Omega, R_{02}=30 \Omega\left(\alpha_{0}=0.7\right), \Delta R_{1} / R_{01} \approx 14.3 \%, \Delta R_{2} / R_{02}=50 \%$. Nominal $\left(\alpha_{0}\right)$, mean ( $\left.\bar{\alpha}\right)$, and most probable ( $\left.\alpha_{m}\right)$ value of the voltage ratio for each divider are indicated by the solid, dashed and dotted vertical lines, respectively.

b) Scaled relative frequency histograms of voltage ratio values for the previously considered dividers with $\alpha_{0}=0.2$ and $\alpha_{0}=$ 0.7 , determined by the Monte Carlo method with 108 trials. Bin sizes are 0.001 for both histograms. Voltage ratio PDFs are approximated by the envelopes of the histograms.

Analytical PDF curves for the two dividers are shown as dashed plots.

Figure 4.b) shows scaled relative frequency histograms of voltage ratio values for the previously considered dividers with $\alpha_{0}=0.2$ and $\alpha_{0}=0.7$, determined by the MCM. Histograms have each been produced with 108 trials, and with a bin size of 0.001 . Analytical PDF curves for the two dividers, shown as dashed plots, fit the envelopes of the histograms almost perfectly.
For realistic resistor tolerances, on the order of $1 \%$, voltage ratio PDFs are much narrower. Assuming uniformly distributed resistances, PDF plots appear less asymmetrical and with sides that seem straight, resembling triangular and trapezoidal distributions. Divergence of and $\alpha_{m}$ from $\alpha_{0}$ is, nevertheless, still present, albeit to a lesser degree. 


\section{PLOTS FOR A DIVIDER WITH NORMALLY DISTRIBUTED RESISTANCES}

Figures 5 and 6 show the scaled relative frequency histograms of voltage ratios determined by the MCM for two dividers: one with $R_{01}=100 \Omega$ (50\% tolerance), $R_{02}=100 \Omega$ (5\% tolerance), and the other with $R_{01}=20$ $\Omega$ (10\% tolerance), $R_{02}=100 \Omega(50 \%$ tolerance $)$. As suggested in section 2 , the values of resistances have been sampled from truncated normal distributions. For the first of the two dividers these are $R_{1} \sim \mathrm{TN}(100$, $\left.(50 / 3)^{2}, 50,150\right), R_{2} \sim \mathrm{TN}\left(100,(5 / 3)^{2}, 95,105\right)$, and for the second $\mathrm{R}_{1} \sim \mathrm{TN}\left(20,(2 / 3)^{2}, 18,22\right), R_{2} \sim \mathrm{TN}(100$, $\left.(50 / 3)^{2}, 50,150\right)$. Histograms have each been produced with 108 trials, with a bin size of 0.001 . Smoothness of the histograms allows the shapes of voltage ratio PDFs, approximated by histogram envelopes, to be easily observed. Even though the overall shape of the PDFs is bell-like, similar to that of a normal distribution, there is also a marked asymmetry of PDFs in both cases. Nominal, mean and most probable values of voltage ratios are indicated by the solid, dashed, and dotted vertical lines, respectively. Here too resistance tolerances have been overstated to make the asymmetry of the plots and the divergence of $\bar{\alpha}$ and $\alpha \mathrm{m}$ from $\alpha_{0}$ noticeable.

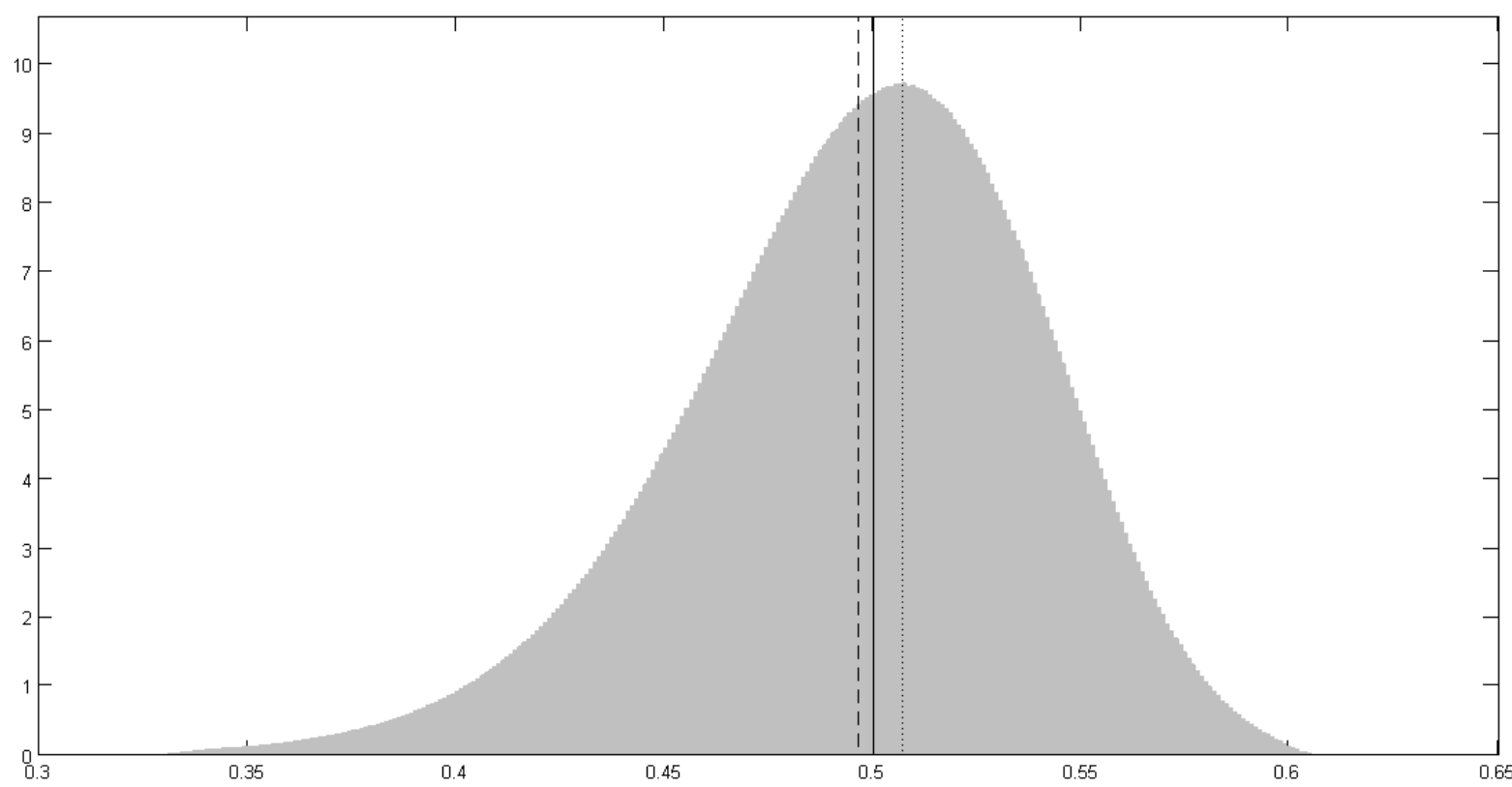

Figure 5. Scaled relative frequency histogram of voltage ratio values for a two-resistor divider with normally distributed resistances $\left(R_{1} \sim \mathrm{TN}\left(100,(50 / 3)^{2}, 50,150\right), R_{2} \sim \mathrm{TN}(100,(5 / 3) 2,95,105)\right)$, determined by the Monte Carlo method with 108 trials. Bin size is 0.001 . Nominal $\left(\alpha_{0}\right)$, mean $(\bar{\alpha})$, and most probable $\left(\alpha_{\mathrm{m}}\right)$ value of the voltage ratio are indicated by the solid, dashed and dotted vertical lines, respectively.

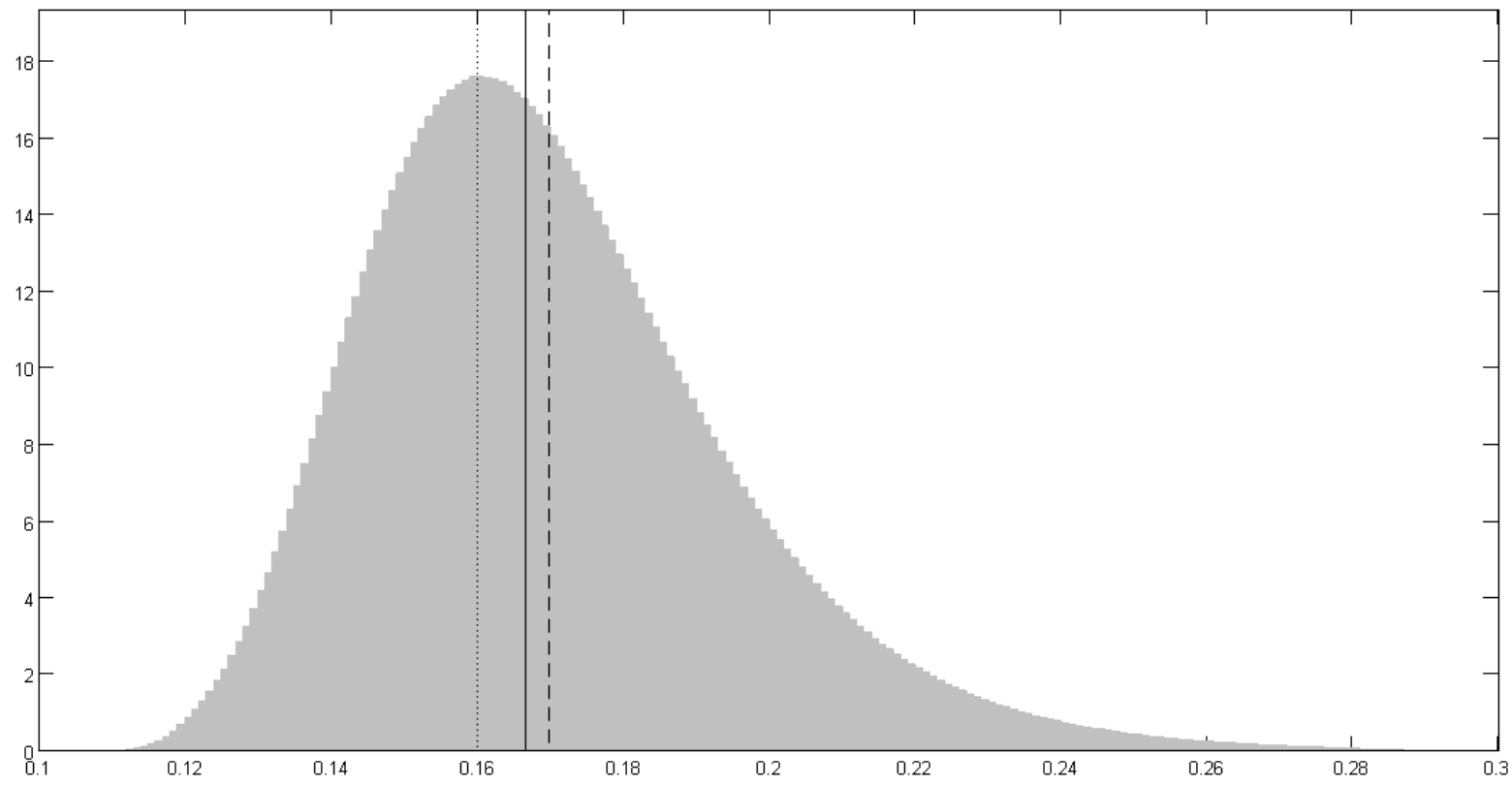

Figure 6. Scaled relative frequency histogram of voltage ratio values for a two-resistor divider with normally distributed resistances $\left(R_{1} \sim \operatorname{TN}\left(20,(2 / 3)^{2}, 18,22\right), R_{2} \sim \mathrm{TN}\left(100,(50 / 3)^{2}, 50,150\right)\right)$, determined by the Monte Carlo method with 108 trials. Bin size is 0.001 . Nominal $\left(\alpha_{0}\right)$, mean $(\bar{\alpha})$ and most probable $\left(\alpha_{m}\right)$ value of the voltage ratio are indicated by the solid, dashed and dotted vertical lines, respectively. 


\section{CONCLUSION}

Within the framework of mathematical theory of probability, the fact that resistors are manufactured with a certain tolerance is taken to mean that the corresponding resistance can be treated as a random variable, with a probability density function (PDF) assigned to it. An analytical expression for the PDF of the voltage ratio for a two-resistor divider with uniformly distributed resistances has been derived in this paper. Plots of this theoretical PDF show excellent agreement with corresponding results obtained by numerical (Monte Carlo) simulations, which use randomly generated values of resistances to calculate the value of the voltage ratio. This agreement suggests that Monte Carlo simulation can be used in cases when the resistances have distributions other than uniform, which are hard to treat analytically. Assuming that the resistances follow truncated normal distributions, Monte Carlo simulations have been used for obtaining plots of the voltage ratio PDF, which is represented by the envelope to the scaled histogram of voltage ratio values.

Whether resistances are assigned uniform or normal distributions, the resulting PDF of the divider's voltage ratio is asymmetrical, with the exception of the case when resistances have equal nominal values and eqaul tolerances. This asymmetry is caused by the non-linearity of the divider's circuit function. It gives rise to a deviation of the mean and the most probable value from the nominal value of the voltage ratio. The degree of asymmetry of the resultant PDF and the difference between the nominal, mean and most probable values depend on specific nominal resistances, as well as on their tolerances. Relative deviation of the mean from the nominal value can generally be either positive or negative.

\section{ACKNOWLEDGMENT}

The Ministry of Education and Science of the Republic of Serbia supported this work under contract 171007.

\section{REFERENCES}

[1] M. Grabe, Measurement Uncertainties in Science and Technology, Springer, 2005.

[2] K. Stanković, M. Vujisić, D. Kovačević, P. Osmokrović, "Statistical analysis of the characteristics of some basic mass-produced passive electrical circuits used in measurements", Measurement 44 (2011) 1713-1722.

[3] M. Vujisić, K. Stanković, P. Osmokrović, A statistical analysis of measurement results obtained from nonlinear physical laws, Applied Mathematical Modelling 35 (2011) 3128-3135.

[4] E. Ć. Dolićanin, I. S. Fetahović, Monte Carlo optimization of redundancy of nanotechnology computer memories in the conditions of background radiation, Nuclear Technology and Radiation Protection, 33 (2), pp. 208-216, 2018.

[5] A. S. Čaršimamović, A. Z. Mujezinović, Z. F. Bajramović, I. M. Turković, M. P. Košarac, Low frequency electric field radiation level around highvoltage transmission lines and impact of increased voltage values on the corona onset voltage gradient, Nuclear Technology and Radiation Protection, 33 (2), pp. 201-207, 2018.

[6] Ć. B. Dolićanin, K. Dj. Stanković , D. Ć. Dolićanin, B. B. Lončar, "Statistical treatment of nuclear counting results", Nucl. Technol. Radiat. Prot. 26-2 (2011) 164-170.

[7] K. Dj. Stanković, M. Lj. Vujisić, Lj. D. Delić, "Influence of tube volume on measurement uncerainty of GM counters", Nucl. Technol. Radiat. Prot. 25-1 (2010) 46-50.

[8] D. V. Hinkley, "On the Ratio of Two Correlated Normal Random Variables". Biometrika 56 (1969) 635-639.

[9] G. Marsaglia, "Ratios of Normal Variables and Ratios of Sums of Uniform Variables", JASA 60 (1965) 193-204.

[10] T. Pham-Gia, N. Turkkan, E. Marchand, "Density of the Ratio of Two Normal Random Variables and Applications", Communications in Statistics: Theory and Methods 35 (2006) 1569-1591.

[11]S. Nadarajah, "On the Ratio $X / Y$ for Some Elliptically Symmetric Random Variables", Journal of Multivariate Analysis 97 (2006) 342-358.

[12]D. Kamerud, "The random variable $X / Y, X, Y$ normal", The American Mathematical Monthly 85 (1978) 207.

[13]L. S. Perazić, Č. I. Belić, D. B. Arbutina, Application of an electronegative gas as a third component of the working gas in the Geiger-Muller counter, Nuclear Technology and Radiation Protection, 33 (3), pp. 268-274, 2018.

[14] N. M. Kartalović, T. M. Stojić, D. V. Brajović, P. V. Osmokrović, The determination of the mean value of the non-homogenous background radiation and the measurement uncertainty using welchsatterthwaite equation, Nuclear Technology and Radiation Protection, 32 (4), pp. 371-374, 2017.

[15] S. V. Crowder, R. D. Moyer, "A two-stage Monte Carlo approach to the expression of uncertainty with non-linear measurement equation and small sample size", Metrologia 43 (2006) 34-41.

[16] M. G. Cox, B. R. L. Siebert, "The use of a Monte Carlo method for evaluating uncertainty and expanded uncertainty", Metrologia 43 (2006) S178-S188.

[17] G. Wübbeler, M. Krystek, C. Elster, "Evaluation of measurement uncertainty and its numerical calculation by a Monte Carlo method", Meas. Sci. Technol. 19 (2007) 1-4.

[18] M. D. Obrenović, M. M. Pejović, D. R. Lazarević, N. M. Kartalović, The effects induced by the gamma-ray responsible for the threshold voltage shift of commercial p-channel power VDMOSFET, Nuclear Technology and Radiation Protection, 33 (1), pp. 81-86, 2018.

[19]E. M. Fort, H. E. Pietsch, Aging of Insulation by Thermal and Electrical Stresses, Electrical/ Electronics Insulation Conference Proc., 1975, pp. 143, IEE Publication No. 75 CH 1014-0-EF54. 
[20] Polužanski, V. S., Kovačević, U. D., Nikolić, B. D., Algorithm for calculating influence of power transformer oil temperature change on the accuracy of all-acoustic non-iterative partial discharge localization, FME Transactions, 46 (2), pp. 183193, 2018.

[21] Todorović, R. B., Škartić, D. M., Bajramović, Z. M., Stanković, K. D., The influence of magnetic field shape on dielectric characteristics of vacuum switches, FME Transactions, 45 (1), pp. 135-141, 2017.

\section{ПРОБАБИЛИСТИЧКА АНАЛИЗА УРЕБАЈА ЗА РАЗДВАЈАҢЕ ОДНОСА НАПОНСКОГ РАЗДЕЛНИКА}

\section{Д. Арбутина, А. Васић-Миловановић, У. Коваһевић}

Толеранција модерних отпорника обично варира од $0.1 \%$ до $1 \%$. Са пробабилистичке тачке гледишта то значи да се одговарајући отпор може посматрати као случајна променљива са одговарајућом функцијом густине расподеле вероватноће (PDF). Добијен је израз за PDF за однос преноса дво-отпорничког разделничког напона, када је отпорима у разделнику додељена униформна расподела. Графикони добијени аналитичким изразима, за различите комбинације номиналних отпора и толеранције двају отпорника, упоређени су са онима добијеним нумеричким симулацијама. Асиметрични карактер добијеног резултантног PDF-a, узрокован нелинеарношћу функције разделничког кола, имплицира да се номинална, средња и највероватнија вредност разделничког односа могу разликовати. За нормалну расподелу отпора у двоотпорничком разделнику, аналитички приступ постаје сложен, док Монте Карло симулације лако дају графиконе напонских односа PDF-а и израчунавају вредности њихових параметара. 